J. M. Hastings \& L. M. Corliss (U.S.A.). Magnetic structure of $\mathrm{MnCr}_{2} \mathrm{O}_{4}$.

Y. Hamaguchi, S. Komura, N. Kunitomi \& M. Sakaмото (Japan). Magnetic properties and structures of uranium-3 $d$ transition metal alloys.

B. G. Lyashenko, D. F. Litvin, I. M. Puzey \& J. G. Aвov (U.S.S.R.). Neutron-diffraction investigation of order-disorder in the alloys ferrum-nickel and ferrumcobalt.

E. F. Bertaut, A. Delapalme, F. Forrat, G. Roult, F. De Bergevin \& R. Pauthenet* (France). Studies of magnetic structures at the nuclear center of Grenoble.

I. I. Y AMSIN, N. V. Belov* \& YU. Z. NoziK(U.S.S.R.). Atomic and magnetic structure of manganese ferrites.
R. A. Alikhanov (U.S.S.R.) (paper read by R. P. Ozerov). Neutronographic study of $\mathrm{NiCO}_{3}$.

R. D. Lowde (U.K.). Magnetic inelastic scattering of neutrons.

T. Riste (Norway). Some experiments on magnetic inelastic scattering of neutrons.

A. Murasik, K. Ruta-Wala \& A. Wanic (Poland) (paper read by T. RISTE). Investigation of magnons in franklinite by the neutron-scattering method.

B. N. Brockhouse, L. N. Becka, K. R. Rao \& A. D. B. Woods* (Canada). Crystal field spectra in rare earth oxides.

D. Cribier, B. Jacrot \& G. Parette (France). Critical scattering of neutrons by nickel.

\title{
Conference in Nishinomiya (near Osaka), Japan, 3 and 4 October 1961
}

The expected presence of a relatively large number of foreign crystallographers and physicists in Japan attending the Kyoto Symposium (see preceding report) had made the Crystallographic Society of Japan decide to organize an International Conference on Scientific Information in the Fields of Crystallography and Solid-State Physics. This meeting was held at the Kwansei Gakuin University, Nishinomiya, on 3 and 4 October. Formally the Interna. tional Union of Crystallography had no responsibility in the organization of the Conference. However, the topics were of immediate interest to the Commissions on Crystallographic Data, on Acta Crystallographica and on Structure Reports. Therefore assistance from the Union had been sought that these Commissions be adequately represented at the meeting, and, on an informal basis, the Union participated through these Commissions in the planning of the programme.

About sixty scientists from eight countries attended the Conference, and most of them took part in the often lively discussions which followed the papers. The meeting was opened on Tuesday 3 October by the President of the Crystallographic Society of Japan, T. WatanabÉ, and his speech was followed by an address of welcome by I. NitTa. At the beginning of the afternoon session the President of the Union, P. P. Ewald, read a message from the Union.

During three half-day sessions nineteen papers were given, which are listed at the end of this report. The contributions were divided between papers by specialists in various aspects of documentation work, and papers by crystallographers dealing with specific documentation problems in crystallography and solid-state physics. Special mention may be made of the introductory lecture of J. D. BernaL, who unfortunately could not be present himself. This paper contained a number of ideas and suggestions with respect to scientific communication and documentation, which might be tried in the field of crystallography, this field being comparatively young, and while intrinsically it is a well-limited system of thought, extrinsically it stands at the cross roads of various other fields. Mimeographed abstracts of most papers had been distributed to the participants in advance; more detailed proceedings will be published by the Crystallographic Society of Japan, to appear early in 1962. These proceedings will include the full text of the papers as well as of the discussions.

During the Conference two panel discussions were held.
The first of these dealt with the ASTM Powder Data Compilation, and took place at the end of the afternoon session on Tuesday 3 October. The second was held at the end of the Conference on Wednesday morning 4 October, its topic being the compilation Crystal Data.

On Tuesday evening the participants enjoyed a dinner at the Takarazuka Hotel, which was offered by the President of the Crystallographic Society of Japan. An excursion to Nara on Wednesday afternoon, and a dinner at the Nara Hotel, concluded the Conference. The participants in the meeting, and in particular those from abroad, owe a deep debt of gratitude to their Japanese hosts for the efficient organization and the most generous hospitality received throughout their stay in Japan.

\section{List of Contributions}

J. D. BeRnAL (U.K.) (paper presented by O. KenNaRD). Introductory lecture.

H. L. BRownson (U.S.A.). Documentation needs of scientists.

K. Hirayama (Japan). Time required, cost and personal for documentation.

G. Waddington (U.S.A.). Organized numerical data compilation in the U.S.A.

H. Chimara (Japan). Activities of the Chemical Abstracts Service.

P. P. EWALD (U.S.A.). Origin of the Strukturbericht.

O. Kennard (U.K.). Activities of the [IUCr] Commission on Crystallographic Data.

A. J. C. Wirson (U.K.). Activities of the [IUCr] Commissions on Acta Crystallographica and on Structure Reports.

J. Wyart (France). Activities of the Centre de Documentation in France.

H. O'DANIEL (Germany). The organization of abstracting and documentation in Germany concerning international crystallographic work.

W. L. FINK (U.S.A.). Activities of the Joint Committee on Chemical Analysis by Powder Diffraction Methods. I. X-ray data.

W. C. Bigerow (U.S.A.). Activities of the Joint Committee on Chemical Analysis by Powder Diffraction Methods. II. Problems in collecting, organizing and indexing electron-diffraction data.

O. Kennard (U.K.). Remarks from the [IUCr] Commission on Electron Diffraction to the Commission on Crystallographic Data. 
N. V. Belov (U.S.S.R.). Activities of the Russian organization for documentation.

V. Hovr (Finland). Scientific documentation in the fields of crystallography and solid-state physics in Finland.

Y. NAKAMura (Japan). Activities of the Japan Documentation Society and other organizations in Japan.
T. Watanabí (Japan). Efforts of the Japanese National Commission for Structure Reports and Crystal Data.

D. U. Mrzoguchi (Japan). Translation difficulties, with special reference to abstracting Japanese literature.

D. P. Shommaker (U.S.A.). Report from the [IUCr] Commission on Crystallographic Computing.

\section{Notes and News}

Announcements and other items of crystallographic interest will be published under this heading at the discretion of the Editorial Board. The notes (in duplicate) should be sent to the General Secretary of the International Union of Crystallography (D. W. Smits, Mathematisch Instituut, University of Groningen, Reitdiepskade 4, Groningen, The Netherlands).

\section{Spring and Summer Schools on Grystallography}

The I.U.Cr. Commission on Crystallographic Teaching has collected the following information about Spring or Summer Schools to be held in 1962:

\section{Santiago (Ghile): 15 March-end of May}

An advanced course on Crystal-Structure Analysis will be given by Prof. M. J. Buerger (M.I.T.) at the Crystallography Laboratory of the University of Chile. This course is intended for people who already have some experience in this subject. A small number of post-graduate students can be accepted, limited by the laboratory facilities available. There will be no registration fees.

Applications and enquiries: Centro de Investigaciones de Cristalografía, Instituto de Fisica y Matematicas, Universidad de Chile, Casilla 2777, Santiago, Chile.

\section{Chicago (U.S.A.): 4-15 June}

The Illinois Institute of Technology offers its annual Summer School in X-ray Diffraction Analysis from 4 to 15 June. Two one-week courses:

Course I: The powder method (4-8 June). [Laboratory procedures for identification, indexing, quantitative analysis and precision measurements of polycrystalline materials.]

Course II: Advanced methods (11-15 June). [Applications of the reciprocal lattice concept to crystal orientation, preferred orientation studies, residual stress measurements, single-crystal methods and other laboratory methods.] Attendance limited to 20 students.

Information and registration: Prof. L. V. Azaroff, Dept. of Metallurgical Engineering, Illinois Institute of Technology, Technology Center, Chicago 16, Ill., U.S.A.

\section{Uppsala (Sweden): 31 July-26 August}

Prof. P. O. Löwdin organizes a Summer School on Quantum Chemistry and Solid State Physics during the period 31 July-26 August.

Information: Prof. P. O. Löwdin, Institute of Quantum Chemistry, University of Uppsala, Sweden.

\section{London, July}

A course in Applied Microscopy will be organized by McCrone Associates and will last a fortnight (the dates are not quite finally fixed). This course will have a strong crystallographic basis and will include several lectures and practicals devoted to crystallography, as a part of analytical microscopy.

Informations: McCrone Associates, 3 Port Hall Mews, Dyke Road, Brighton 5, England.

\section{Oxford (England), 7-18 August}

A course in Computing methods in crystallography will be organized by Dr J.S. Rollet.

Informations: Dr J. S. Rollet, Oxford University Computing Lab., 9 South Parks Road, Oxford, England.

\section{Glasgow (Scotland), September}

A conference of $X$-ray analytical methods will be held in the Department of Chemistry at the University of Glasgow early in September. The object of this conference will be to provide a facility for the discussion of X-ray diffraction and $X$-ray spectrographic methods of analysis, both from a theoretical and a practical view-point.

Informations: Prof. J. M. Robertson, Chemistry Dept., The University, Glasgow, W. 2, Scotland. 